\title{
KULTUR HUKUM TENAGA KESEHATAN TERHADAP BAHAYA PENULARAN INFEKSI DI RUMAH SAKIT
}

\author{
Endang Sutrisno $\triangle^{1}$, Sudarminto $\measuredangle^{2}$, Djuhariah $\measuredangle^{3}$, Irma Gamawati $Z^{4}$ \\ Program Studi Ilmu Hukum Pascasarjana Universitas Swadaya Gunung Jati

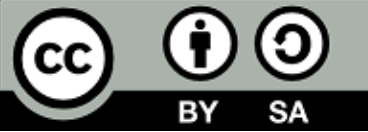

DOI: http://dx.doi.org/10.33603/hermeneutika.v3i2

Diterima: 2 Juni 2020; Direvisi: 30 Juli 2020; Dipublikasikan: Agustus 2019

\begin{abstract}
Abstrak: Tenaga kesehatan memiliki risiko besar tertular penyakit infeksi atau Healthcare Associated Infection (HAIS) sebab berhubungan langsung dengan pasien yang menjadi sumber penularan di rumah sakit. Kultur hukum yang dibangun untuk tenaga kesehatan harus konstruktif, sehingga dapat memperoleh akses untuk aspek perlindungan hukum terhadap bahaya penularan infeksi apabila mereka mengetahui, memahami dan melaksanakan regulasi pencegahan dan pengendalian infeksi di rumah sakit. Pendekatan penelitiannya socio-legal. dengan tujuan mengkaji pemahaman hukum tenaga kesehatan di rumah sakit dan bentuk perlindungan hukumnya. Temuan penelitian mendeskripsikan tenaga kesehatan di Rumah Sakit Umum sudah mengetahui adanya peraturan terhadap bahaya penularan infeksi, tetapi belum sepenuhnya memahami muatan substansi peraturan perundang-undangan tersebut.
\end{abstract}

Kata Kunci: Tenaga Kesehatan; Kultur Hukum; Perlindungan Hukum.

\footnotetext{
${ }^{1}$ Endang Sutrisno

Email: endangsutrisno94@gmail.com

${ }^{2}$ Sudarminto

Email: pascaunswagati16@gmail.com

${ }^{3}$ Djuhariah

Email: djuhariah@unswagati.ac.id

${ }^{4}$ Irma Gamawati

Email: irmaunswagati@gmail.com
} 



\section{PENDAHULUAN}

Bidang pembangunan kesehatan harus dilakukan secara terintegrasi dan komprehensif harus diperhatikan pula aspek-aspek lain misalnya ekonomi, budaya, hukum hal ini sangat beralasan mengingat persoalan kesehatan menyangkut kepentingan yang paling fundamental sifatnya.

Pada dimensi lain masyarakat berhak atas kesehatan bagi dirinya sendiri termasuk bagi para penyedia layanan kesehatan itu sendiri. Tenaga kesehatan juga berhak mendapat kesempatan untuk sehat karena dalam kesehariannya mereka mendapatkan risiko yang besar tertular penyakit infeksi dari pasiennya.

Pihak-pihak yang terlibat dalam pelayanan medis harus sepenuhnya memperoleh kepastian jaminan akan rasa aman dalam menjalankan profesinya sebagaimana yang telah dinormatifkan dalam muatan produk hukum yang mengatur masalah tenaga kesehatan.

Mereka yang telah memberikan tenaganya serta kompetensinya di bidang kesehatan serta keahliaannya melalui tahapan pendidikan yang telah ditempuhnya di bidang kesehatan memiliki kewenangan dalam melakukan tindakan medis, harus mendapatkan jaminan rasa aman dan kenyamanan untuk melakukan profesinya. Pemahaman tersebut menyangkut tenaga kesehatan serta asisten tenaga kesehatan, kedua bentuk profesi tersebut kaidah hukum telah memberikan pengaturan yang jelas.

Tenaga kesehatan memiliki risiko besar tertular penyakit infeksi karena di dalam mengerjakan tugasnya tenaga kesehatan ini berhubungan langsung dengan pasien yang menjadi sumber penularan.

Infeksi Terkait Pelayanan Kesehatan (Health Care Associated Infections) yang selanjutnya disingkat HAIs adalah infeksi yang terjadi pada pasien selama perawatan di rumah sakit dan fasilitas pelayanan kesehatan lainnya dimana ketika masuk tidak ada infeksi dan tidak dalam masa inkubasi, termasuk infeksi dalam rumah sakit tapi muncul setelah pasien pulang, juga infeksi karena pekerjaan pada petugas rumah sakit dan tenaga kesehatan terkait proses pelayanan kesehatan di fasilitas pelayanan kesehatan. HAIs tidak terbatas infeksi pada pasien saja, tetapi juga infeksi pada petugas kesehatan yang didapat pada saat melakukan tindakan perawatan pasien. Khusus untuk infeksi yang terjadi atau di dapat di rumah sakit, selanjutnya disebut sebagai infeksi rumah sakit (Hospital infection $)^{5}$.

Petugas kesehatan dapat tertular penyakit infeksi karena adanya proses transmisi. Transmisi atau cara penularan infeksi kepada pasien maupun tenaga kesehatan dapat melalui beberapa cara yaitu : (1) kontak : langsung dan tidak langsung, (2) droplet, (3) airborne, (4) melalui vehikulum (makanan, air/minuman, darah) dan (5) melalui vektor (biasanya serangga dan binatang pengerat). Salah satu contoh Hospital infection diantaranya adalah Tuberculosis, HIV AIDS, Hepatitis B maupun $C$ dan beragam penyakit infeksi lainnya.

Berdasarkan hal tersebut menegaskan persoalan pemahaman hukum serta bentuk perlindungan hukumnya untuk tenaga kesehatan berdasarkan norma hukum yang berlaku menjadi persoalan penting, sehingga ada upaya memberikan jaminan rasa aman dan kepastian hukum pada saat bekerja menjadi faktor yang sangat penting sehingga hukum mampu mencapai tujuan yang dikehendaki. The government must be able to give affirmation to the community, the law that is made leads to the interests of

\footnotetext{
5 Radjab Nasution Chairul, dkk, 2011, Pedoman Pencegahan dan Pengendalian Infeksi di Rumah Sakit dan Fasilitas Pelayanan Kesehatan Lainnya Kesiapan Menghadapi Emerging Infectious Disease, Cetakan ketiga, Kementrian Kesehatan RI, Jakarta, hlm 1-1.
} 
the community and oriented towards social justice ${ }^{6}$.

\section{PROBLEM RESEARCH}

Fakta keberlakuan norma hukum dalam bentuk produk perundang-undangan di bidang kesehatan yang mengatur pencegahan serta pengendalian infeksi di fasilitas pelayanan kesehatan dan norma keselamatan dan kesehatan kerja di Rumah Sakit, serta kaidah hukum menyangkut masalah penyelenggaraan pelayanan penyakit yang disebabkan oleh akibat kerja, menimbulkan pertanyaan bagaimanakah kultur hukum yang terbangun dan bentuk perlindungan hukum yang dapat diberikan kepada tenaga kesehatan di Rumah Sakit Umum terhadap bahaya penularan infeksi. Tujuan yang ingin dicapai melalui kajian ini menelaah pemahaman hukum dan bentuk perlindungan hukumnya untuk tenaga kesehatan di Rumah Sakit berkenaan dengan bahaya penularan infeksi, hal ini penting mengingat keberlakuan kaidah hukum tujuannya untuk membangun rasa aman, keadilan, kesejahteraan dan kemanfaatan untuk masyarakat.

\section{METODE PENELITIAN}

Penelitian ini dikaji untuk mengetahui interpretasi makna dari peraturan hukum yang berlaku, disertai implementasi kepatuhan hukum tenaga kesehatan terhadap bahaya penularan infeksi yang ada di Rumah Sakit Umum. Analisis terhadap permasalahan yang diteliti diambil dari hasil pengamatan dan pengumpulan informasi dari para narasumber yang sudah ditentukan.

Permasalahan hukum yang diteliti yaitu nilai-nilai yang diyakini sebagai pedoman untuk perilaku tenaga kesehatan, dalam hal penularan infeksi di Rumah Sakit sebab yang diteliti perilaku hukum meliputi kesadaran hukum, kepatuhan hukum,

\footnotetext{
${ }^{6}$ Endang Sutrisno, Relations Between Legal Culture and Economic Empowerment among Marginalized Group of Farmers,Journal of Legal, Ethical and Regulatory Issues, Volume 22, Issue 3, June 2019, page 22-3-329.
}

motivasi hukum, komunikasi hukum dan bagaimana hukum diterapkan untuk mengetahui gejala-gejala sosial atau fenomena sosial hingga akhirnya tercipta suatu perlindungan hukum terhadap tenaga kesehatan tersebut. Oleh karena itu, pendekatan dalam penelitian ini adalah socio-legal. Hukum yang diteliti dikonsepkan dalam bentuk pemaknaan tenaga kesehatan terhadap value dari norma hukum tertulis yaitu Peraturan Menteri Kesehatan nomor 27 Tahun 2017 tentang Pedoman Pencegahan dan Pengendalian Infeksi di Fasilitas Pelayanan Kesehatan; Peraturan Menteri Kesehatan nomor 66 Tahun 2016 tentang Keselamatan dan Kesehatan Kerja di Rumah Sakit, dan Peraturan Menteri Kesehatan nomor 56 Tahun 2016 tentang Penyelenggaraan Pelayanan Penyakit Akibat Kerja, sebab Pemerintah telah menetapkan regulasi tentang pencegahan penyakit infeksi di rumah sakit untuk memberikan perlindungan hukum kepada para tenaga kerjanya. Pelaksanaan pedoman pencegahan dan pengendalian infeksi ini sangat dipengaruhi oleh tingkat pemaknaan dari masing-masing tenaga kesehatan yang menimbulkan kepatuhan dalam menjalankannya. Selain itu tuntutan akreditasi rumah sakit pun meminta supaya pedoman ini dilaksanakan demi tercapainya tujuannya yaitu perlindungan dan kepastian hukum.

\section{LANDASAN TEORETIK}

Law is an important element in the development of politics and it makes the relationship with government policy clearer. Through legislation, the Government determines what it can do and what not to do. Law defined as legislation is a system of norms where the rule of law is arranged in unity within a hierarchical manner. The lower legal norms should not be contradictory to the higher legal norms ${ }^{7}$. Hal

\footnotetext{
${ }^{7}$ Endang Sutrisno - Isnaeni Jazilah, The Licensing Policy for Groundwater Extraction and Management for Hospitality Industry in Cities in Developing
} 
ini meneguhkan pernyataan kaidah hukum yang dibangun oleh Negara harus mampu mewujudkan tujuannya, sekalipun hukum dibangun oleh kekuatan pembangunan politik tetapi pada akhirnya norma-norma tersebut harapannya dapat diterapkan dan ditegakan tanpa harus terjadinya lemahnya kesadaran hukum dan kepatuhan hukum masyarakat, asas hukum tetap harus dipegang teguh ketentuan-ketentuan hukum yang ada dan telah berlaku menjadi dasar hukum untuk peraturan di level bawahnya. Fakta keberlakuan tatanan hukum tentang perlindungan tenaga kesehatan terhadap bahaya penyakit menular pada saat bekerja di rumah sakit harus dipahami dalam koridor menjamin rasa aman dan berkeadilan serta berkemanfaatan harus diimbangi dengan regulasi teknis di tingkat bawah dalam konteks tatanan implementasinya, kebijakan harus dijadikan alternatif pemecahan masalah dengan disertai penegakan hukumnya.

Tujuan dirumuskannya kaidah hukum dalam tataran mewujudkan ketertiban, rasa nyaman, keamanan, keadilan, kepastian hukum serta kebergunaan kaidah hukum tersebut diberlakukan di tengah-tengah masyarakat, tetapi pada dimensi lain bahwa norma bekerjanya hukum tersebut dipengaruhi oleh banyak faktor sebab sub sistem hukum bagian dari sub sistem-sub sistem lain.

Tenaga kesehatan sangat rentan terkena penularan infeksi. Tenaga kesehatan harus memiliki pengetahuan dan pemahaman yang memadai terhadap perlindungan hukum terhadap bahaya penularan infeksi ini. Regulasi seperti Undang-Undang Nomor 44 Tahun 2009 tentang Rumah Sakit; Undang-Undang Nomor 29 Tahun 2004 tentang Praktik Kedokteran; Undang-Undang Nomor 36 Tahun 2009 tentang Kesehatan; Undang-

Countries, Journal Water Policy, IWA Publishing, Vol.21, Issue 3 June 2019, page 1-10.
Undang Nomor 36 Tahun 2014 tentang tenaga Kesehatan; Peraturan Menteri Kesehatan Nomor 66 Tahun 2016 tentang Keamanan Dan Keselamatan Kerja Di Rumah Sakit; Peraturan Menteri Kesehatan Nomor 27 Tahun 2017 tentang Pedoman Pencegahan Dan Pengendalian Infeksi Di Fasilitas Pelayanan Kesehatan Dan Peraturan Menteri Kesehatan Nomor 56 Tahun 2016 tentang Penyelenggaraan Penyakit Akibat Kerja harus diketahui dan dipahami dengan baik oleh tenaga kesehatan. Proses bekerjanya hukum tersebut, bergantung kepada komponen kultur hukum sebab masalah ini memegang peran sentral untuk bekerjanya sistem hukum di masyarakat.

Kultur hukum memegang peran penting dalam sistem hukum yang berlaku, disamping komponen substansi, struktur hukum mengingat kultur hukum merupakan motornya keadilan pada saat norma hukum tersebut bekerja di masyarakat. For want of a better term, we can call some of these forces the legal culture. It is the element of social attitude and value. The phrase "social forces" is itself an abstraction; in any event, such forces do not work directly on the legal system. People in society have needs and make demands; these sometimes do and sometimes do not invoke legal processdepending on the culture ${ }^{8}$. Factors of limited number of human resources and factor of economic become the reason not to implemented the law ${ }^{9}$.

Perlindungan hukum tenaga kesehatan dalam penularan infeksi sangat berkaitan dengan aspek kesadaran dan

\footnotetext{
${ }^{8}$ Lawrence M. Friedman, the Legal System A Social Science Perspective, (New York: Russel Sage Foundation, 1975, hlm.15.

${ }^{9}$ Endang Sutrisno - Hanari Fajarini, Legal Culture of Pharmacist in the Perspective of Pharmaceutical Services Standard In Pharmacies, Jurnal Dinamika Hukum Faculty of Law Universitas Jenderal Soedirman Purwokerto, Vol.16.No.2 May 2016, page. 152 .
} 
kepatuhan hukum, hal ini dideskripsikan jika tenaga kesehatan tersebut memiliki kesadaran hukum untuk menjalankan profesinya sesuai dengan standar operasional prosedur dan pedoman untuk pencegahan serta pengendalian penularan infeksi yang mungkin dapat terjadi di lingkungan rumah sakit. Perlindungan hukum ini diwujudkan seiring dengan adanya kesadaran hukum dan kepatuhan hukum terhadap pedoman dan peraturan yang berlaku untuk tenaga kesehatan.

Penegakan sistem hukum sangat dipengaruhi oleh komponen substansi, struktur dan kultur hukum, sebab hal tersebut mengarah kepada pentingnya perlindungan hukum tersebut terbentuk. Persoalan kultur hukum sebagai salah satu komponen penting yang harus diperhatikan, termasuk kultur hukum tenaga kesehatan yang menyangkut ide, gagasan, persepsi, pandangan, perilaku, opini yang dapat mempengaruhi permasalahan apakah hukumnya akan ditegakan atau disimpangi, apakah hukumnya akan dipatuhi atau dilanggar, hal itu semua sangat bergantung kepada kultur hukum dari tenaga medis tersebut. Pola perilaku tenaga kesehatan yang bekerja di rumah sakit sangat menentukan terwujudnya perlindungan hukum terhadap penularan infeksi. Dan tentunya sebagai penentu adalah budaya hukum tenaga kesehatan, apakah memiliki kesadaran dan kemauan kuat untuk mematuhi pedoman ataupun peraturan yang ada.

Dari sisi struktur hukum yang berarti lembaga hukum yang ada untuk menegakan kaidah hukum tentang penularan infeksi, dan rumah sakit harus mampu memberikan dukungan penuh untuk menentukan implementasi perlindungan hukum tenaga kesehatan yang bekerja didalamnya sebab dukungan tersebut sangat berpengaruh terhadap implementasi perlindungan hukum tenaga kesehatan.

\section{PEMBAHASAN}

Pemahaman tentang penularan infeksi ini adalah segala sesuatu yang diketahui dan dipahami mengenai apa itu infeksi, bagaimana dapat timbul infeksi, faktor-faktor yang menyebabkan terjadinya penyakit infeksi di rumah sakit, bagaimana siklus atau pola penyakit infeksi menular, dan apa yang harus dilakukan untuk mencegah penularan infeksi ini. Pengetahuan dasar penyakit infeksi ini merupakan tolak ukur awal kewaspadaan dari masing-masing tenaga kesehatan sekaligus gambaran apakah tenaga kesehatan ini paham tentang bahaya penularan infeksi di rumah sakit dapat menular kepadanya dan mengetahui sejauh mana upaya yang dilakukannya agar terlindungi. Bahasan ini lebih mengarah pada kemampuan dasar pengetahuan medis masing-masing tenaga kesehatan itu sendiri.

Faktor ini didefinisikan dengan bagaimana informan memaknai hukum yang berlaku mengenai pencegahan penularan infeksi. Kemudian bagaimana penafsiran tenaga kesehatan terhadap aturan-aturan yang diterapkan. Hal yang kemudian perlu diungkap adalah bagaimana menjalankan aturan yang diterapkan dalam kehidupan keseharian. Pemahaman menjadi fokus pembahasan untuk menemukan kesenjangan dari yang tersurat dalam aturan dengan realitas sosial yang secara faktual ada di masyarakat.

Perlindungan hukum tenaga kesehatan ini dipayungi oleh regulasi pemerintah diantaranya, Pasal 50 UndangUndang Nomor 29 Tahun 2004 tentang Praktik Kedokteran telah diatur dengan jelas bahwa dokter dan dokter gigi mempunyai hak untuk memperoleh perlindungan hukum. Namun perlindungan hukum yang didapatkan dokter dan dokter gigi ini semata-mata diperoleh apabila mereka telah melaksanakan tugasnya sesuai dengan standar profesinya. Hal ini menerangkan bahwa bentuk perlindungan hukum yang ada diperoleh sebagai bentuk melaksanakan kewajiban sesuai dengan standar operasional prosedur yang ada. Permasalahannya kemudian adalah mengenai kesadaran dan kepatuhan dari para dokter dan para dokter gigi inilah yang 
dipertaruhkan sehingga dapat tercapai kepastian hukum.

Norma hukum yang lain, secara tertulis produk hukum dalam bentuk peraturan perundang-undangan kesehatan telah diatur bahwa orang menjalankan profesi di bidang kesehatan dan memberikan pelayanan kesehatan diberikan perlindungan secara hukum akan tindakannya, oleh sebab sedang menjalakan profesinya. Hal ini sangat beralasan mengingat dalam menjalankan pekerjanyaa ada jaminan perlindungan hukum terhadap tindakannya dan dijamin oleh undangundang, jadi tidak diperkenankan bila seorang bidan bekerja layaknya kompetensi dokter ataupun sebaliknya yang tidak sesuai dengan kompetensinya. Di dalam peraturan ini lebih ditekankan masalah profesionalitas tenaga kesehatan sebab jika profesionalisme terjaga, maka perlindungan hukum terhadap bahaya penularan infeksipun dapat terwujud. Kaidah hukum kesehatan secara tertulis telah memberikan kepastian terhadap adanya jaminan perlindungan hukum ini sepanjang dalam menjalankan kewajiban berdasarkan kriteria dan parameter yang jelas menyangkut dimensi tolok ukur profesi, pelayanan profesi, serta tolok ukur prosedur operasional dan sesuai dengan ketentuan Peraturan Perundang-undangan.

Dalam Peraturan Menteri Kesehatan Nomor 66 Tahun 2016 tentang Keselamatan dan Kesehatan Kerja Rumah Sakit, ditegaskan kembali bahwa sumber daya manusia rumah sakit dalam hal ini tenaga kesehatan dijamin keselamatan dan kesehatannya selama bekerja sebagai konsekuensi positif yang muncul setelah rumah sakit menerapkan keselamatan dan kesehatan kerja Rumah Sakit. Fasilitas Pelayanan Kesehatan harus melakukan upaya pencegahan serta menghindari terjadinya kemungkinan terjadinya infeksi, berkaitan dengan pasien, petugas, pengunjung, dan masyarakat. $\begin{array}{rrr}\text { Rumah } & \text { Sakit sebagai institusi } \\ \text { pelayanan } & \text { kesehatan } & \text { yang }\end{array}$ menyelenggarakan pelayanan kesehatan perorangan secara paripurna yang menyediakan pelayanan rawat inap, rawat jalan, dan gawat darurat merupakan lingkungan yang sangat strategis untuk terjadinya penularan penyakit infeksi diantara orang-orang yang terlibat di sekelilingnya seperti pasien ke pasien lainnya, pasien ke pendamping pasien, pasien ke tenaga kesehatan, maupun pasien ke pengunjung rumah sakit.

Pemahaman tenaga medis terhadap norma hukum masih dalam tataran mengetahui sehingga harus ada upaya dalam tahap internalisasi untuk sampai kepada derajat kepatuhan, tidak hanya sebatas kesadaran hukum. Hal ini penting mengingat pada persepktif ini peroalan kultur hukum menjadi sangat dominan berperan. Hukum menjadi multidimensi pemahamannya, the are factors that influence law enforcement. These factors have a neutral meaning so that the positive or negative impact lies in certain factors that influence it ${ }^{10}$.

Hukum sebagaimana fungsinya untuk mengatur kehidupan sosial menjadi lebih tertata membawa konsekuensi hak dan kewajiban didalamnya. Jika kita mengambil hak kita dalam hukum tentunya kita harus melaksanakan terlebih dahulu kewajiban hukum kita. Kewajiban hukum dalam hal pencegahan penularan infeksi adalah dengan melakukan pelayanan medis sesuai dengan prosedur yang berlaku. Sebagai seorang tenaga kesehatan, tuntutan untuk

10 Endang Sutrisno -Taty Sugiarti - Novani Ambarsari Pratiwi, Environmental :aw Enforcement in Hazardous-Waste Management in West Java Indonesia: A Critical Trajectory of Green and Anthropogenic-Based Environmental Policy Orientations, International Journal of Scientific \& Technology Research, Vol.8, Issue 08, August 2019, page. 430 . 
mengetahui aturan yang ada baik sebelum, pada saat maupun sesudah melakukan tindakan medis amatlah perlu. Tenaga medis haruslah memiliki sertifikat kompetensi, terregistrasi dan memiliki surat izin praktek sebelum memberikan pelayanan medis. Kemampuan yang dimiliki oleh seorang tenaga kesehatan juga sewajarnya dikukuhkan dalam bentuk kompetensi tenaga kesehatan. Kompetensi tenaga kesehatan diajukan terlebih dahulu ke Komite Medik Rumah Sakit untuk di validasi dan di uji melalui proses yang disebut kredensial. Setelah mendapatkan keabsahan dari proses kredensial Komite Medik Rumah Sakit maka kemudian ketua komite medik merekomendasikan kewenangan klinis tenaga kesehatan tersebut kepada direktur rumah sakit.

Setiap tenaga kesehatan memiliki kewajiban untuk mematuhi pedoman, panduan, maupun standar pelayanan di rumah sakit sebaik-baiknya agar tidak terjadi kelalaian maupun kesalahan yang membuat tenaga kesehatan tersebut terinfeksi penyakit infeksi dari pasien maupun lingkungannya.

Kesadaran hukum dan kepatuhan hukum merupakan faktor yang menentukan bagi sahnya hukum, faktor tersebut sangat bergantung kepada kultur hukum tenaga kesehatan yang terbentuk. Ide, gagasan, persepsi, pandangan dan perilaku terhadap regulasi yang mengatur masalah perlindungan hukum untuk tenaga kesehatan dalam hal melaksanakan profesinya, harus dijadikan bahan acuan mendasar.

Untuk mendapatkan gambaran pemahaman tenaga kesehatan terhadap norma hukum yang mengatur upaya pencegahan dan pengendalian bahaya penularan infeksi seluruh tenaga medis telah mengetahui tentang kaidah hukum tersebut hal ini dengan asumsi kepada tahapan prosedur pada saat awal penerimaan karyawan baru, tak terkecuali tenaga medis, keperawatan maupun bidan, dilakukan seleksi dan diberikan orientasi umum rumah sakit yang sama atau terstandar. Materi yang terdapat dalam orientasi umum tersebut diantaranya adalah materi tentang Pencegahan dan Pengendalian Infeksi (PPI). Melalui kegiatan tersebut, diharapkan para tenaga kesehatan dapat mengetahui dan memahami tatanan hukum tentang pencegahan infeksi saat bekerja sehingga mampu dibangun kesadaran hukum dan kepatuhan hukum yang baik.

Kultur hukum yang terbangun tenaga kesehatan terkadang lalai dalam upaya pencegahan dan pengendalian infeksi hal ini dengan persepsi yang menyederhanakan pentingnya tindakan untuk melakukan cuci tangan diantara tenaga kesehatan. Rendahnya pemahaman terhadap kepatuhan untuk melakukan tindakan cuci tangan menjadi salah satu indikator kultur hukum yang terbangun menjadi negative. Mencuci tangan harus dilakukan pada saat tertentu yaitu sebelum kontak dengan pasien, sebelum tindakan aseptic, setelah kontak darah dan cairan tubuh, setelah kontak dengan pasien dan setelah kontak dengan lingkungan sekitar pasien.

Secara normatif dalam ketentuan hukum yang mengatur upaya pencegahan serta pengendalian infeksi berkenaan dengan fasilitas pelayanan kesehatan mengamanatkan untuk melakukan cuci tangan dengan sabun biasa/ antimikroba dan bilas kembali dengan air yang tetap mengalir.

Kultur hukum tenaga kesehatan terhadap norma hukum tersebut belum sepenuhnya mampu mengkonstruksikan realitas sosial yang menuju kea rah pencapaian kesadaran hukum dan kepatuhan hukum.

Pengalaman pribadi tenaga kesehatan dan pola interaksi sosial yang dialami tentang cuci tangan sangat mempengaruhi pilihan untuk mematuhi atau tidak mematuhi aturan mengenai cuci tangan. Apabila mencuci tangan ini sudah menjadi budaya dalam kegiatan pelayanan medisnya sehari-hari, tidakan cuci tangan menjadi suatu kebiasaan. Kebiasaan cuci tangan dalam kegiatan pelayanan medis memiliki tujuan yang baik demi terselenggaranya patient safety dan 
pencegahan terhadap bahaya penularan infeksi. Nilai yang terkandung dalam aktivitas cuci tangan, harus dilestarikan menjadi budaya kebiasan dalam pola hidup keseharian tenaga kesehatan.

Fakta sosial lain bahwa kesadaran tenaga kesehatan dalam menggunakan Alat Pelindung Diri (APD) masih rendah, hal ini terbukti dengan masih ditemukannya tenaga kesehatan yang menggunakan masker tidak sesuai ketentuan. Masker tersebut hanya dipakai bila tenaga kesehatan tersebut memeriksa pasien, sedangkan setelahnya masker tersebut dibuka dan dibiarkan menggantung di leher tenaga kesehatan tersebut atau tidak langsung dibuang seluruhnya. Kebiasaan demikian memudahkan terjadinya penularan infeksi dan membuat pemakaian alat pelindung diri berupa masker tersebut tidak berguna. Masker selayaknya digunakan sebagai alat pelindung diri bagi tenaga kesehatan dan penggunaannya harus memenuhi prosedur agar menghasilkan efek proteksi yang optimal. Kultur hukum yang terbentuk terhadap pemahaman norma hukum positif dari tenaga kesehatan menjadi persoalan yang harus disadarkan kembali untuk tetap patuh kepada tatanan yang ada dalam penanganan tindakan medis.

Orang menggunakan hukum atau tidak menggunakan hukumnya, kepatuhan dan pelanggaran terhadap norma hukum sangat bergantung kepada komponen kultur hukumnya.

Budaya hukum menjadi komponen yang sangat penting guna memutar struktur statis dan koleksi statis norma-norma menjadi tubuh dari hukum yg hidup, artinya bahwa budaya hukum akan menentukan kapan, mengapa dan dimana masyarakat menggunakan hukum, institusi hukum atau proses hukumnya. budaya hukum diartikan pula, berupa sikap dan nilai-nilai yang menjadi pegangan public, yang akan menentukan apakah pengadilan akan dimanfaatkan atau tidak apabila menghadapi suatu masalah hukum. budaya hukum adalah keseluruhan faktor-faktor yang menentukan bagaimana hukum memperoleh tempat yang sesuai dan dapat diterima di dalam kerangka budaya masyarakat ${ }^{11}$.

Kultur hukum terhadap pemahaman hukum penting untuk dapat memberikan perlindungan hukum tenaga kesehatan di rumah sakit, merujuk pada peraturan perundang-undangan yang berlaku seperti Undang-Undang nomor 44 Tahun 2009 tentang Rumah Sakit, Undang-Undang nomor 29 tahun 2004 tentang Praktik Kedokteran, Undang-Undang Nomor 36 Tahun 2009 tentang Kesehatan, dan Undang-Undang Nomor 36 Tahun 2014 tentang Tenaga Kesehatan. Selain itu, regulasi yang dibentuk pun memperhatikan aspek sosial seperti keadaan kesehatan tenaga kerja yang berkorelasi positif dengan peningkatan kinerja pegawai.

\section{SIMPULAN}

Tenaga kesehatan di rumah sakit pada umumnya sudah mengetahui adanya peraturan terhadap bahaya penularan infeksi tetapi belum sepenuhnya memahami peraturan peundang-undangan yang berhubungan dengan bahaya penularan infeksi sebagaimana yang tercantum dalam peraturan perundang-undangan yang berlaku. Kultur hukum tenaga kesehatan masih belum secara optimal memahami pentingnya norma hukum pengendalian dan pencegahan infeksi. Pemahaman terhadap hukum dari tenaga kesehatan masih sebatas mengetahui saja sehingga penerapan kaidah hukum masih harus dibangun. Faktor kesadaran hukum dan kepatuhan hukum menjadi persoalan yang harus ditangani secara serius di rumah sakit.

\footnotetext{
11 Endang Sutrisno, Pemaknaan Budaya Hukum: Menggagas Kesejahteraan Masyarakat. Penerbit in Media, Bogor, 2019, hlm 23.
} 


\section{Buku-Buku:}

\section{DAFTAR PUSTAKA}

Endang Sutrisno, 2019, Pemaknaan Budaya Hukum: Menggagas Kesejahteraan Masyarakat. Penerbit in Media, Bogor.

Lawrence M. Friedman, 1975, the Legal System A Social Science Perspective, (New York: Russel Sage Foundation.

Radjab Nasution Chairul, dkk, 2011, Pedoman Pencegahan dan Pengendalian Infeksi di Rumah Sakit dan Fasilitas Pelayanan Kesehatan Lainnya Kesiapan Menghadapi Emerging Infectious Disease, Cetakan ketiga, Kementrian Kesehatan RI, Jakarta.

\section{Jurnal Internasional:}

Sutrisno, Endang, and Hanari Fajarini. 2016. "LEGAL CULTURE OF PHARMACIST IN THE PERSPECTIVE OF PHARMACEUTICAL SERVICES STANDARD IN PHARMACIES." Jurnal Dinamika Hukum.

Sutrisno, E., \& Jazilah, I. (2019). The licensing policy for groundwater extraction and management for hospitality industry in cities in developing countries. Water Policy. https://doi.org/10.2166/wp.2019.087

Siswoyo, M., Permana, I., Hidayat, M. S., \& Sutrisno, E. (2019). Government Policy on Additional Income to Civil Servants. https://doi.org/10.2991/isseh18.2019 .19

Sutrisno, E. (2014). Implementasi Pengelolaan Sumber Daya Pesisir Berbasis Pengelolaan Wilayah Pesisir Secara Terpadu Untuk Kesejahteraan Nelayan (Studi di Perdesaan Nelayan Cangkol Kelurahan Lemahwungkuk Kecamatan Lemahwungkuk Kota Cirebon ) . Jurnal Dinamika Hukum. https://doi.org/10.1158/10780432.CCR-06-2072

Sutrisno, E. (2015). Tracing the Performance of Law in Indonesia (A Perspective of Thomas Kuhn's Normal Science). Journal of Law, Policy, and Globalization, 37, 126.

Yolanda, N., Sutarih, A., \& Hartini, S. I. (2020). Acquisition company. International Journal of Scientific and Technology Research, 9(4), 22922294. 